\title{
Thymic self-antigens for the design of a negative/tolerogenic self-vaccination against type 1 diabetes Vincent Geenen ${ }^{1}$, Marie Mottet ${ }^{1}$, Olivier Dardenne ${ }^{1}$, Hamid Kermani ${ }^{1}$, Henri Martens ${ }^{1}$, Jean-Marie Francois ${ }^{2}$, Moreno Galleni ${ }^{2}$, Didier Hober ${ }^{3}$, Souad Rahmouni ${ }^{4}$ and Michel Moutschen ${ }^{4}$
}

Before being able to react against infectious nonself-antigens, the immune system has to be educated in the recognition and tolerance of neuroendocrine proteins and this critical process takes place only in the thymus. The development of the autoimmune diabetogenic response results from a thymus dysfunction in programing central self-tolerance to pancreatic insulin-secreting islet $\beta$ cells, leading to the breakdown of immune homeostasis with an enrichment of islet $\beta$-cell reactive effector $T$ cells and a deficiency of $\beta$-cell specific natural regulatory $\mathrm{T}$ cells (nTregs) in the peripheral Tlymphocyte repertoire. Insulin-like growth factor 2 (IGF-2) is the dominant member of the insulin family expressed during fetal life by the thymic epithelium under the control of the autoimmune regulator (AIRE) gene/protein. The very low degree of insulin gene transcription in normal murine and human thymus explains why the insulin protein is poorly tolerogenic as demonstrated in many studies, including the failure of all clinical trials that have attempted immune tolerance to islet $\beta$ cells via various methods of insulin administration. On the basis of the close homology and crosstolerance between insulin, the primary T1D autoantigen, and IGF-2, the dominant self-antigen of the insulin family, a novel type of vaccination, so-called 'negative/tolerogenic selfvaccination', is currently being developed for the prevention and cure of T1D. If this approach were found to be effective for reprograming immunological tolerance in T1D, it could pave the way for the design of other self-vaccines against autoimmune endocrine diseases, as well as other organspecific autoimmune diseases.

\footnotetext{
Addresses

${ }^{1}$ University of Liege Center of Immunology (CIL), Laboratory of Immunoendocrinology, Institute of Pathology CHU-B23, B-4000 LiegeSart Tilman, Belgium

${ }^{2}$ University of Liege Center of Protein Engineering (CIP), Institute of Chemistry B6c, B-4000 Liege-Sart Tilman, Belgium

${ }^{3}$ University Lille 2, Faculty of Medicine, CHRU Lille, Laboratory of Virology/UPRES EA 3610 Viral Pathogenesis of Type 1 Diabetes, Institut Hippocrate, 59037 Lille, France

${ }^{4}$ Immunology and Infectious Diseases Unit, GIGA-Research, University of Liege, Liege-Sart Tilman, Belgium
}

Corresponding author: Geenen, Vincent (vgeenen@ulg.ac.be)

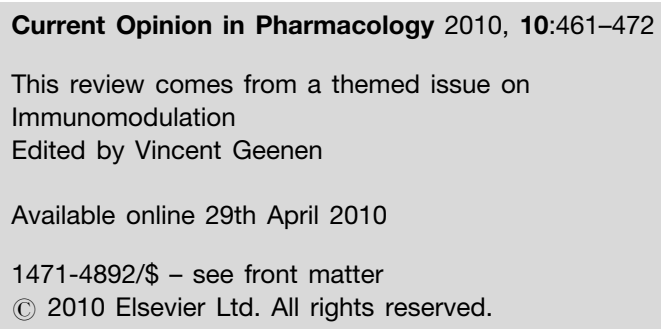

This review comes from a themed issue on Immunomodulation

Edited by Vincent Geenen

Available online 29th April 2010

$1471-4892 / \$$ - see front matter

(C) 2010 Elsevier Ltd. All rights reserved.

DOI 10.1016/j.coph.2010.04.005

"Autoimmune disease can be a depressing subject. In Shakespearian terms, 'it is a tale told by an idiot... signifying nothing'. In more modern metaphor, it is an error made at random in an enormous, delicately programmed computer. Nature has no other way of handling genetic error than by eliminating the faulty, and the physician handling autoimmune diseases can expect no help from her."

Sir F. MacFarlane Burnet, 1972

\section{Introduction}

In 1965, our late Belgian colleague Willy Gepts observed inflammatory infiltrates of mononuclear cells invading Langerhans' islets in the pancreas of deceased young diabetic patients [1]. In a prophetical analysis, he discussed his innovative results with the following words: 'It seems probable that, in the pancreas of acute diabetics, we had the opportunity to catch the final stages of a process which has been going on for an indefinite time, perhaps from birth on'. Since this pioneering work, research conducted worldwide has firmly established that type 1 diabetes (T1D) - previously called juvenile diabetes, and insulin-dependent diabetes - is the final result of a highly selective autoimmune response that generates an inflammation (insulitis), followed by the death of insulin-secreting islet $\beta$ cells in the pancreas. Incidence of T1D peaks around $10-14$ years and this disease affects \pm 20 million people worldwide (approximately 10\% of all patients with diabetes mellitus). The mean prevalence of T1D in Europe is about 8 new cases per year and per 100000 individuals, but this prevalence is five to six times higher in Scandinavian countries, particularly in Finland. 


\section{Humoral and cellular immune responses of T1D}

The discovery of autoantibodies directed against Langerhans' islet cells was a crucial step for further demonstrating the autoimmune nature of the pathogenic process in T1D [2]. Since then, the nature of autoantigens targeted by these autoantibodies has been well defined, and the three major T1D-related autoantigens are (pro)insulin, the $65-\mathrm{kDa}$ isoform of glutamic acid decarboxylase (GAD65), and the tyrosine phosphatase IA-2. The isletspecific cation efflux transporter Zn'T8 (Slc30A8) and chromogranin A were also recently reported as important autoantigens in T1D [3,4]. However, from these autoantigens, only antigenic epitopes derived from (pro)insulin are specific of pancreatic islet $\beta$ cells. Furthermore, there is now ample evidence that autoimmunity to (pro)insulin is central to autoimmune diabetes pathogenesis both in nonobese diabetic (NOD) mice and in humans [5,6]. Anti-insulin, anti-GAD65, and anti-IA-2 autoantibodies are very reliable markers of the autoimmune response targeting $\beta$ cells. Serum from more than $90 \%$ of children with recent-onset T1D contains antibodies against one or several of these autoantigens. Their high predictive value is also established since they can be detected several years before the clinical signs of insulin deficiency. The predictive value of autoantibodies against several autoantigens is higher than high titers of one single autoantibody. If the three autoantibodies are detected in one individual, the risk of developing T1D is at least 80 times higher than in the general population. The combination of autoantibodies with susceptible genetic alleles of the major histocompatibility (MHC) class II locus further increases this predictive value. Such prediction is very useful for clinical studies targeted at T1D prevention given the relatively low incidence of this disease $[7,8]$. However, the pathogenic significance of T1D-related autoantibodies is rather low, if not absent [9], and the principal effectors of $\beta$-cell autoimmune destruction are CD4+ and CD8+ T lymphocytes [10]. Investigation of specific $\mathrm{T}$-cell responses in T1D patients is very difficult because of the low frequency in the peripheral T-cell pool of autoreactive $T$ cells specific of epitopes derived from (pro)insulin, GAD65 or IA-2. However, the development of sensitive and specific techniques, such as enzyme-linked immunosorbant spot assays (ELISpot) and tetramers of class I/II HLA molecules complexed with T1D-related epitopes, has already provided very significant data that further document the importance of T-cell mediated mechanisms in T1D pathogenesis [11,12].

\section{Genetic factors in T1D pathogenesis}

T1D is the polygenic autoimmune disease that has been most intensively investigated at the genetic level. Knowledge of genetic loci that determine susceptibility to T1D is important for identifying pathogenic pathways, for improved prediction of the disease, and for selection of potential pharmacological targets. The balance between susceptibility and resistance alleles determines individual predisposition to T1D. The most significant part $( \pm 50 \%)$ of genetic susceptibility to T1D resides in the HLA class II region on chromosome $6 \mathrm{p} 21$, as recognized by pioneering studies $[13,14]$. The major susceptibility in this region is conferred by the specific HLA class II haplotypes DR4DQA1*0301-DQB1*0302 (DQ8 molecule) and DR3$D Q A 1 * 0501-D Q B 1 * 0201$ (DQ2 molecule). In contrast, the allele $D Q B 1 * 0602$ (DQ6 molecule) confers dominant protection against T1D. Theoretically, HLA class I proteins present antigens that are processed from endogenous proteins to CD8+ T cells, while HLA class II proteins present antigens issued from exogenous proteins to CD4+ T cells. Consequently, it has long been difficult to explain the relationship between insulin and T1D genetic susceptibility located in the HLA class II region. This problem was solved when very elegant crystallographic studies showed that a dominant insulin epitope (Ins B9-23) is presented in the binding pocket of DQ8 and DQ2 proteins [ $\left[5^{\circ}\right]$. Since then, a comprehensive scan of the whole HLA region, combined with potent statistical methods, has also linked T1D susceptibility to HLA class I genes HLA-B and HLA-A [16].

Other genetic linkage and association studies have identified a second locus for T1D susceptibility that corresponds to a high polymorphic mini-satellite constituted by a variable number of tandem repeats (VNTR) $[17,18]$. This VNTR is embedded on chromosome 11p15, and controls the transcription of the insulin (INS) and insulinlike growth factor 2 (IGF2) genes downstream. Short VNTR class I alleles contain 20-63 repeats of 14-15 base pairs, while intermediate class II and long class III alleles include 64-139 and 140-210 repeats, respectively. VNTR class I alleles are associated with TID susceptibility, whereas class III alleles confer protection.

The CTLA4 gene region on chromosome $2 \mathrm{q} 33$ is also associated with susceptibility to T1D [19]. The signaling between B7, expressed by professional antigen-presenting cells (APCs) such as dendritic cells (DCs) and cytotoxic T-lymphocyte-associated protein 4 (CTLA-4), expressed by $\mathrm{T}$ cells, plays a pivotal role in peripheral T-cell tolerance. CTLA-4 is expressed neither by thymocytes (thymic $\mathrm{T}$ cells) nor by resting $\mathrm{T}$ cells, but it is detectable after antigen-mediated T-cell activation, and downregulates responses of activated $\mathrm{T}$ cells. Citla4 deletion in mice results in an extremely severe lymphoproliferative and an autoimmune phenotype with lethal multiorgan tissue destruction $\left[20^{\circ}\right]$.

Another mutation in a non-HLA gene conferring significant susceptibility to T1D is a variant of the lymphoid tyrosine phosphatase Lyp gene (PTPN22), a suppressor of T-cell activation $\left[21^{\circ}\right]$. Lyp normally interacts with a Cterminal Src kinase (Csk) complex to dephosphorylate 
positive regulatory tyrosines and downregulate signaling from the T-cell receptor (TCR) pathway. The minor allele derived from the single-nucleotide polymorphism (SNP) differs in a single but crucial amino acid residue (R620W) involved in the interaction of Lyp with Csk. Interestingly, the same variant R620W also increases risk to other common autoimmune diseases, such as rheumatoid arthritis, Graves' disease, and systemic lupus erythematosus [22]. However, the variant PTPN22 620W is a gain-of-function mutant, since it is associated with a higher catalytic activity of the encoded Lyp, a marked decrease of T-cell response to antigen stimulation, CD25 expression, and IL-10 secretion from TCR stimulation, and an increase in peripheral memory CD4+ T cells [23,24]. The role of this mutation in the pathogenesis of T1D and other autoimmune diseases remains to be further elucidated.

Different studies, including a genome-wide association analysis, have identified association of T1D with noncoding SNPs on the chromosome $10 \mathrm{p} 15$ region containing CD25, which encodes the high-affinity $\alpha$ chain of the IL2R complex [ $\left.25^{\circ}\right]$. Further mapping of the association between the IL2RA locus and T1D supported a role of IL2R $\alpha$ in the pathogenesis of the disease, most possibly through modulation of regulatory T-cell (Treg) activity [26].

An association has also been found between T1D and a polymorphism of the IGF2 receptor gene (IGF2R), which seems to be subject to parental imprinting since only maternal alleles at this polymorphism are associated with the disease [27]. Human T1D differs from other common autoimmune disorders, which preferentially affect females (e.g. autoimmune diabetes in the NOD mouse). Evidence was also recently provided for an association between T1D and polymorphisms in CYP27B1, which encodes $1 \alpha$-hydroxylase, the enzyme that transforms $25(\mathrm{OH})$ vitamin $\mathrm{D}$ into bioactive $1,25(\mathrm{OH})_{2}$ vitamin D3 [28].

\section{Environmental factors}

Many observations strongly support an important influence of environmental factors in the pathogenesis of T1D: the lack of complete concordance in monozygotic twins (approximately $30 \%$ of them develop T1D), the fact that less than $10 \%$ of genetically susceptible individuals progress to overt disease, the increase in T1D annual incidence observed in recent years, as well as the higher incidence of new cases between March and October. Geographic localization also determines important variation in T1D incidence when one compares high-rated Northern European countries such as Finland (40-45 new cases $/ 100000$ inhabitants per year) and low-rated countries such as Venezuela and China (0.1/100 000 inhabitants per year) [29]. Migrant populations moving from low-incidence countries tend to acquire the same risk as the inhabitants of the welcoming countries. For example, T1D annual incidence among Pakistani children living in United Kingdom is identical to that observed among English children (e.g. 11.7/100 000 inhabitants versus 1/100 000 inhabitants in Pakistan) [30]. However, migrant studies also provide evidence for the importance of genetic background, since the risk of T1D remains increased for people migrating from high-incidence areas to low-risk countries [31]. In Europe, a 10-fold North-South gradient is observed in T1D incidence (with the noticeable exception of Sardinia for unknown reasons). Owing to the relative homogeneity of European populations, such a gradient cannot result from genetic differences only. Although childhood T1D was rare and lethal at the beginning of the 20th century, a recent European Community Concerted Action Program (EURODIAB) has shown that new T1D cases in European children under 5 years is predicted to double between 2005 and 2020, and prevalence of T1D cases under 15 years will rise by $70 \%$ [32]. As discussed by the authors, these rapid changes over relatively short periods of time cannot be explained by changes in prevalence of susceptibility genes. Among environmental influences, several studies have pointed to modern lifestyle habits, increased weight and height, increased caesarean deliveries and, most perhaps importantly, the 'hygiene hypothesis'. This hypothesis proposes that the decrease of childhood infections and other environmental stimuli impair the healthy development and diversification of the neonatal immune repertoire, inducing higher incidence of allergic and autoimmune diseases later in life $\left[33^{\bullet}, 34^{\circ}\right]$. In the NOD mouse, a classic animal model of T1D, the susceptibility to autoimmune diabetes is also greatly affected by environmental effects, and the incidence of the disease is much higher when NOD mice are bred in a germ-free environment [35].

A number of viral infections have also been associated with the subsequent development of T1D including enteroviruses, congenital rubella, mumps, cytomegalovirus, Epstein-Barr virus, and varicella zoster virus [36,37]. Epidemiological studies have provided the strongest evidence that coxsackievirus (CVB) and other enterovirus infections are frequent events in subjects who ultimately develop T1D [38]. CVB4 is the most common serotype detected in prediabetic and diabetic individuals. The CVB4 strain E2 has been isolated from the pancreas of an acutely deceased diabetic child, passed through murine islet $\beta$ cells, and then found to induce a diabetes-like disease after inoculation in mice [39]. Early epidemiologic studies have suggested that CVB may be involved in T1D pathogenesis. Using serological analyses, initial first studies showed that newly diagnosed T1D patients were more frequently positive for CVB4 than control subjects [40,41]. Subsequently, a series of epidemiological studies have confirmed high frequencies of IgM anti-CVB in children recently diagnosed with 
T1D. Thereafter, using RT-PCR detection of the virus genome, Clements et al. showed that $64 \%$ of children at onset of T1D were positive for enteroviruses as opposed to $4 \%$ of controls [42]. In another study, CVB genome was detected in five out of $12(42 \%)$ newly diagnosed T1D patients and in one of $12(8 \%)$ patients during the course of the disease. By contrast, none of 12 T2D patients and none of 15 healthy adults had enterovirus sequences in their blood [43]. The GVB4 strain E2 is able to induce a persistent infection of human islet $\beta$ cells [44], whereas a new isolated CVB4 variant, VD2921, causes a persistent infection of islet $\beta$ cells with a consequent disturbance of proinsulin synthesis and insulin secretion [45]. CVB4 E2 and VD2921 genomes were recently detected by RTPCR in the peripheral blood mononuclear cells (PBMCs) of a majority of T1D children at the onset of their diabetes. The presence of enterovirus RNA in the blood cells of most new T1D children supports the hypothesis that a viral infection is involved in T1D pathogenesis. Interestingly, six out of seven controls positive for CVB4 had been infected by a phylogenetic branch of CVB4 different from the one detected in diabetic patients, suggesting the existence of CVB4-related substrains with different diabetogenic effects [46].

Despite a significant homology between the amino acid sequence 28-50 of P2-C, a nonstructural viral protein of the CVB4 replicative complex, and amino acids 250-273 of the $\beta$-cell autoantigen GAD65, molecular mimicry is not involved in CVB-induced diabetes, as mice with susceptible MHC alleles do not show CVB-induced acceleration of diabetes [47]. Moreover, none of antiGAD65 antibodies produced by lymphocytes isolated from a newly diagnosed T1D patient crossreacted with the protein P2-C itself [48]. Nevertheless, it was shown that a viral epitope mimicking a $\beta$-cell antigen is able to accelerate, but not to prime a diabetogenic autoimmune process [49]. A very recent study has also identified a molecular mimicry between human T-cell epitopes in rotavirus and pancreatic islet autoantigens (GAD65 and IA-2) [50].

An alternative potential mechanism is a CVB-mediated 'bystander' activation of autoreactive T cells against islet antigens; this mechanism was proposed to explain the rapid onset of diabetes in mice carrying a TCR specific for a sequestered islet autoantigen. In that model, CVB induces diabetes by a direct local infection, leading to inflammation, secondary tissue damage, and then release of sequestered islet antigens that are able to stimulate resting autoreactive $\mathrm{T}$ cells [47]. According to those observations, autoreactive $\mathrm{T}$ lymphocytes would gain access to the target islets without being involved in the initial viral insult or in reactivity to the viral antigens [51]. The same group also provided strong evidence that the early innate immune response to CVB4 is responsible for $\beta$-cell damage and the development of diabetes. Indeed, $\beta$ cells became highly susceptible to CVB4 infection and subsequent NK cell response after inhibition of interferon (IFN) signaling by transgenic overexpression in islet $\beta$ cells of suppressor of cytokine signaling 1 (SOCS-1) under the influence of the insulin promoter. The islet $\beta$ cells were secondarily damaged by apoptosis occurring during the innate immune response, rather than by the adaptive B-cell and T-cell responses. Thus, target $\beta$ cell defense critically influences susceptibility to T1D after CVB4 infection [52].

Although the relationships between CVB infection and subsequent T1D development are still debated by some authors, recent studies using PCR techniques with very specific oligonucleotide probes - thus avoiding serological pitfalls and crossreactions - have found substantial evidence for an association between a previous CVB infection and T1D. High levels of IFN- $\alpha$, an indirect indicator of viral infection, were measured in $70 \%$ of 56 new type 1 diabetics, together with positive detection of GVB RNA in $\pm 50 \%$ of the IFN- $\alpha$ positive patients [53]. Somewhat ironically, the association between T1D and viral infections has been recently reinforced by genetic studies that have shown a linkage between T1D susceptibility and host genetic determinants of the antiviral responses such as the antiviral oligoadenylate synthetase (OAS1) and the interferon-induced helicase (IFIH1 or MDA5), which intervenes in innate immunity by recognition of RNA genomes of picornaviruses (such as coxsakieviruses) [54-56]. Therefore, the question of a higher incidence of enterovirus infection during childhood in countries with a high risk of T1D deserves to be further investigated, particularly if one seriously considers the possibility of anti-CVB vaccination as a potential method for T1D prevention in these areas.

\section{The central role of the thymus in self- tolerance of neuroendocrine proteins and the nature of 'neuroendocrine self'}

A major question when addressing the pathogenesis of organ-specific autoimmunity such as T1D is the origin of the self-reactive $\mathrm{T}$ cells that are directed against target antigens of endocrine cells. Among all lymphoid structures, the thymus is an organ that emerged some 500 million years ago, concomitantly or very shortly after recombinase-dependent adaptive immunity, with a specific function of orchestrating central immunological self-tolerance. The thymus is not an endocrine gland, but it crucially stands at the intersection between the immune and neuroendocrine systems. In this organ that is responsible for thymopoiesis, that is, generation of naïve and competent $T$ lymphocytes, the neuroendocrine system regulates the process of $\mathrm{T}$-cell differentiation from very early stages, while in parallel naïve $\mathrm{T}$ lymphocytes are educated to recognize and tolerate neuroendocrine gene/protein families $\left[57,58^{\bullet}, 59\right]$. Therefore, the thymus is a unique organ where a constant conflict occurs 
between ancient, highly conserved, neuroendocrine proteins and a more recently evolved system equipped with recombination machinery for promoting stochastic generation of T-cell response diversity. Contrary to popular opinion, the thymus continues to function throughout life and plays a fundamental role in the recovery of a competent T-cell repertoire after intensive chemotherapy or during highly active antiretroviral chemotherapy in human immunodeficiency virus infection [60,61]. The integrity of the somatotrope growth hormone/IGF-1 axis is known to be important for the maintenance of thymus function in adult life $\left[62^{\circ}\right]$.

The thymus constitutes the central arm of immunological self-tolerance by two essential mechanisms that are intimately associated with, and paradoxically mediated by, the same thymic self-antigens: first, clonal deletion of self-reactive $T$ cells issued from the random recombination of TCR genes (negative selection) and second, generation of self-antigen-specific natural regulatory $T$ cells (nTregs) that are able to inactivate in periphery selfreactive $\mathrm{T}$ cells having escaped intrathymic negative selection $\left[63^{\bullet \bullet}, 64\right]$.

For a long time, peripheral tissue-restricted antigens targeted by autoimmune processes were thought to be sequestered from $T$ cells during their intrathymic differentiation. We and several other groups have demonstrated that thymic epithelial cells (TECs) from different species constitute a site for the promiscuous transcription of a great number of genes encoding tissuerestricted antigens or belonging to neuroendocrine families, such as the neurohypophysial family, tachykinins, neurotensins, somatostatins, atrial natriuretic peptides, and the insulin family. This demonstration has radically changed our common understanding of the pathogenesis of organ-specific autoimmune endocrine diseases such as T1D. From the investigation of intrathymic expression of neuroendocrine-related self-peptide precursor genes, a series of properties can be derived that define the nature of the 'neuroendocrine self'. First, thymic neuroendocrine self-antigens usually correspond to peptide sequences that have been highly conserved throughout the evolution of their related family. Second, a hierarchy characterizes their expression pattern in the thymus. In the neurohypophysial family, oxytocin (OT) is the dominant peptide synthesized by TECs from different species. The binding of OT to its cognate receptor expressed by pre-T cells induces a very rapid phosphorylation of focal adhesion related kinases. This event could play a major role in promoting establishment of synapses between immature $\mathrm{T}$ lymphocytes and thymic APCs, TECs, macrophages, and DCs. With regard to tachykinins, neurokinin A (NKA) - but not substance $\mathrm{P}$ - is the peptide generated from the processing by TEC of the preprotachykinin A $(P P T-A)$ gene product. All the genes of the insulin family are expressed in the thymus accord- ing to a precise hierarchy and topography during fetal life: IGF2 (cortical and medullary TECs) $>I G F 1$ (thymic macrophages) $\gg I N S$ (a few subsets of medullary TECs). This hierarchical pattern is meaningful because the strength of self-tolerance to a protein is proportional to its intrathymic concentration [65]. Third, neuroendocrine precursors are not processed according to the classic model of neurosecretion, but they undergo an antigenic processing for presentation by - or in association with - MHC proteins [ $66^{\bullet \bullet}$ ]. Fourth, most of neuroendocrine self-antigens are transcribed in the thymic epithelium under the control of the autoimmune regulator gene AIRE (see below). Fifth, intrathymic OT transcription precedes OT and vasopressin (VP) expression in hypothalamic magnocellular neurons. Finally, epigenetic regulation of intrathymic gene expression is strongly suggested by the loss of $I G F 2$ parental imprinting and overexpression in human medullary TECs $[67,68]$.

This hierarchy in the organization of the thymic repertoire of neuroendocrine self-antigens is also significant from an evolutionary point of view. Since a series of essential and physiological functions had been established before the appearance of adaptive immunity in cartilaginous fishes, they had to be protected from the risk of autotoxicity inherent to this type of immunity. For example, OT is a 'bonding' peptide that has been implicated at different steps of the reproductive process, and thus for species preservation possibly had to be protected to a greater degree than VP, which controls water metabolism and vascular tone. Along the same line of reasoning, IGF-2 as a major factor in fetal development possibly had to be more protected than insulin, which is 'only' responsible for glucose homeostasis. Nevertheless, because of their close homology, thymic neuroendocrine self-antigens may promote crosstolerance to other members of their respective families. This was recently demonstrated by the weaker tolerance to insulin of $I g f 2^{-1-}$ mice when compared to wild-type mice [ $\left.69^{\circ}\right]$. Further insight into the discrimination between the relative influence of central and peripheral arms of immunological self-tolerance will be gained through the generation of mice with TEC-specific Igf 2 deletion, currently under development in our laboratory.

\section{The central role of a thymus dysfunction in T1D pathogenesis (Figure 1)}

As hypothesized by Burnet in 1973, the essential pathogenesis of autoimmune diseases may first depend on the appearance of 'forbidden' self-reactive clones in the peripheral T-cell repertoire [70]. In 1992, a defect in the process of intrathymic $\mathrm{T}$-cell education to recognize and to tolerate OT was hypothesized to play a pivotal role in the development of hypothalamus-specific autoimmunity leading to 'idiopathic' central diabetes insipidus [71]. The progressive increase in the degree of immune diversity and complexity may explain why failures in self- 
tolerance are increasingly detected during evolution with most such failures occurring in the human species. Since the thymus is the primary site for induction of selftolerance, thorough investigation of the mechanisms responsible for a breakdown of thymus-dependent tolerance should provide the scientific community with important keys to understand the mechanisms underlying the development of autoimmune responses. This was the principal objective of the European FP6 Integrated Project Euro-Thymaide. A number of abnormalities of thymic morphology and cytoarchitecture have been described for several autoimmune disorders. Central tolerance and apoptosis of self-reactive $T$ cells are defective in the thymus of NOD mouse [72,73]. Transcription of insulin-related genes (Ins, Igf1, and Igf2) has been analyzed in the thymus of diabetes-resistant (BBDR) and diabetes-prone (BBDP) rats, another model of T1D. Ins and Igf1 transcripts were detected in all thymi from BBDP and BBDR rats. Igf2 transcripts were also present in the thymus from all BBDR rats, but were not detected in the thymus from more than $80 \%$ of BBDP rats, in close concordance with the incidence $(86 \%)$ of autoimmune diabetes in those rats. This defect in $I g f 2$ transcription in BBDP thymus could contribute to both their lymphopenia (including CD8+ $\mathrm{T}$ cells and suppressor/regulatory RT6+ T cells) and to the absence of central self-tolerance to insulin-secreting islet $\beta$ cells $[74,75]$. Other authors have shown that susceptibility to autoimmune diabetes is correlated with the level of Ins 2 transcription in the mouse thymus [76]. Breeding of Ins $2^{-I-}$ mice onto the NOD background markedly accelerated insulitis and onset of diabetes [77]. In contrast, insulitis and diabetes were considerably reduced in Ins $1^{-1-}$ congenic NOD mice [78]. These observations are explained by the dominance of Ins 2 encoding proinsulin in the murine thymus, while Ins 1 encodes proinsulin in islet $\beta$ cells. In the human species, INS transcripts were measured at lower levels in the fetal thymus with short class I VNTR (variable number of tandem repeats) alleles, a genetic trait of T1D susceptibility as discussed above $\left[79^{\bullet}, 80^{\circ}\right]$. The fundamental role of thymic insulin in mediating central self-tolerance of islet $\beta$ cells was definitively demonstrated by the rapid onset of autoimmune diabetes following thymus-specific deletion of Ins1 and Ins2 through an elegant transgenic construction in mice $\left[81^{\bullet \bullet}\right]$.

The identification of AIRE led to further demonstration that a thymus dysfunction plays a crucial role in the pathogenesis of organ-specific autoimmune diseases $[82,83]$. Loss-of-function AIRE single mutations are responsible for a very rare autosomal recessive disease named autoimmune polyendocrinopathy, candidiasis and ectodermal dystrophy (APECED), or autoimmune polyendocrine syndrome type 1 (APS-1). This syndrome develops in early childhood and is characterized by multiorgan autoimmunity and insufficiency of several endocrine glands such as parathyroids, adrenal cortex, and gonads. AIRE codes for a $54-\mathrm{kDa}$ protein sharing structural characteristics with transcription factors. Its expression is maximal in the thymus, mainly in medullary TECs, but is absent in TECs of NOD mice [84]. Depending on their genetic background, Aire ${ }^{-1-}$ mice exhibit several signs of peripheral autoimmunity, which are associated with a significant decrease in thymic transcription of neuroendocrine genes (including $O t, N p y, \operatorname{Igf} 2$, and Ins2), as well as other tissue-specific genes $\left[85^{\bullet \bullet}, 86^{\bullet \bullet}, 87^{\bullet \bullet}\right]$. Of note, Aire deficiency on NOD background induces both wasting and resistance to diabetes, while autoimmunity severely affects pancreatic exocrine acini [88].

In collaboration with Didier Hober (Laboratory of Virology EA3610, CHRU Lille, France), we have shown that CVB4 is capable to directly infect the epithelial and lymphoid compartments of the human and murine thymus, and to induce a severe thymus dysfunction with massive pre-T-cell depletion and marked upregulation of MHC class I expression by TECs and by CD4+ CD8+ immature thymic $\mathrm{T}$ cells $[89,90]$. Interestingly, outbred mice can be infected with CVB4 following an oral inoculation, which results in systemic spreading of viral RNA and a prolonged detection of CVB4 RNA in thymus, spleen, and blood up to 70 days postinoculation [91]. These findings suggest that thymic CVB4-mediated severe infection could enhance CVB4 virulence through induction of immunological tolerance to CVB4, and consequently may play a role in the breakdown of central self-tolerance to islet $\beta$ cells.

\section{Self-vaccination as an alternative for T1D prevention and cure (Figure 2)}

Given the impossibility to modify the genetic constitution of susceptible individuals and to act efficiently upon most of the environmental influences - except perhaps through a future anti-enterovirus/CVB4 vaccination in high-risk countries - contemporary clinical results still favor an immunomodulatory approach aiming to control the autoimmune response oriented against $\beta$ cells, but without compromising general immunity. Ideally, this autoimmune regulation should be combined with strategies of regeneration of damaged islet $\beta$ cells and the inhibition of the apoptotic process promoted in $\beta$ cells by the autoimmune process. Nevertheless, even after transplantation of $\beta$ cells from allogenic or xenogenic donors, or $\beta$ cells issued from adequate differentiation of embryonic stem cells or induced pluripotent stem cells, the control of autoimmune memory selective of islet $\beta$ cells is an absolute prerequisite both for T1D prevention and for cure. Until now, significant clinical success has been reached only with $\mathrm{Fc}$ receptor $(\mathrm{FcR})$-nonbinding CD3-specific humanized monoclonal antibodies that were shown to preserve endogenous insulin-secreting islet $\beta$-cell mass in recently diagnosed T1D patients 


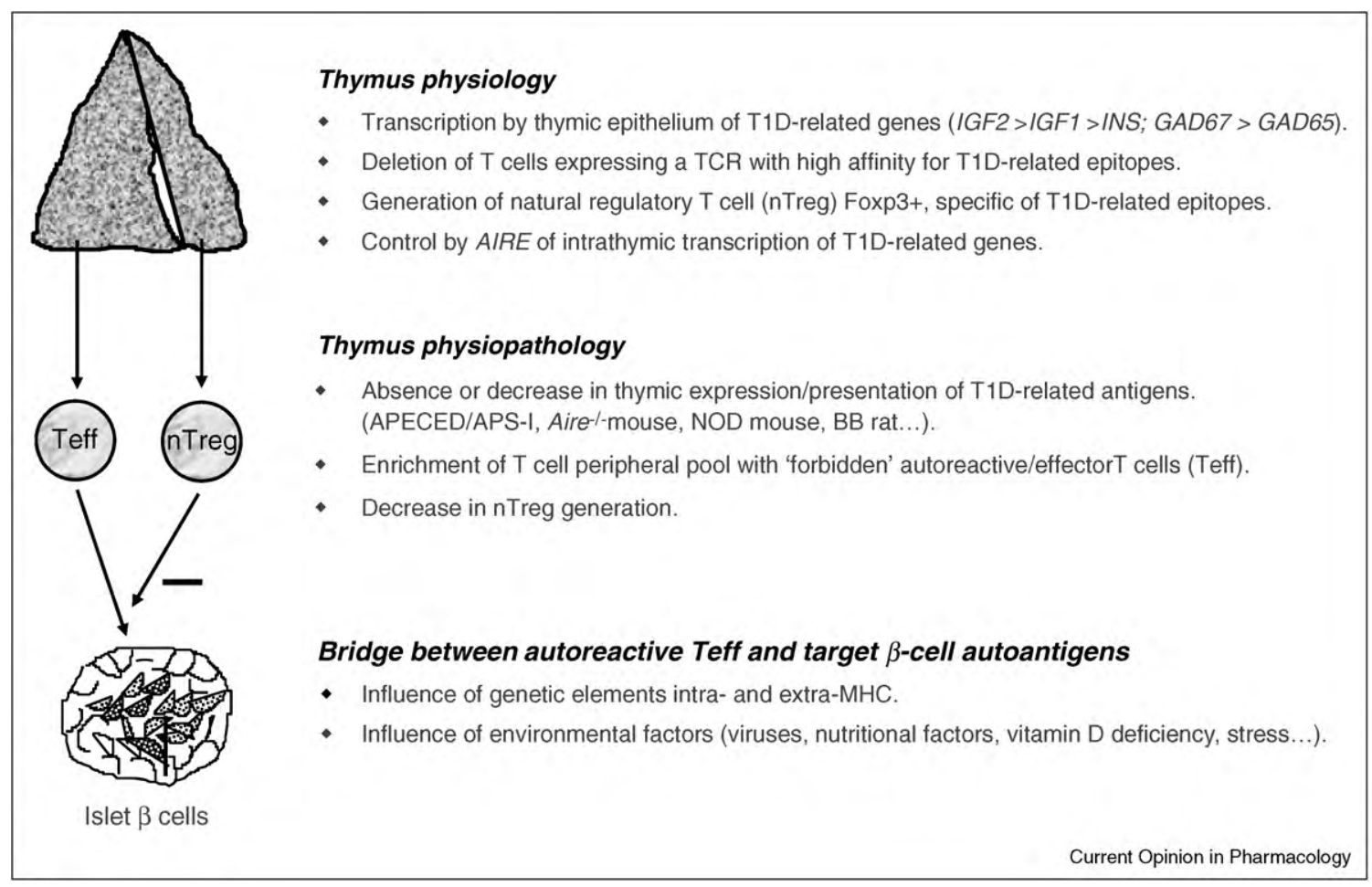

Thymus physiopathology and T1D development. Throughout life, the thymus selects Teff self-tolerant and competent against nonself-antigens, and generates self-specific nTregs. Thymic epithelium transcribes genes encoding T1D-related antigens, as well as other neuroendocrine-related and tissue-restricted antigens, under AIRE control for most of them. Absence or decrease in the presentation of thymic T1D-related antigens (as observed in different animal models of autoimmune diabetes) conducts to the enrichment of the peripheral T-cell pool with 'forbidden' self-reactive T cells bearing TCR directed against T1D-related epitopes, while thymic generation of specific nTregs is severely impaired. Combination of these two events is responsible for the breakdown of central self-tolerance to islet $\beta$ cells. Both genetic and environmental factors are involved in the establishment of a molecular bridge between anti- $\beta$ cell autoreactive Teff and islet $\beta$-cell autoantigens. Once this bridge is formed, the autoimmune pathogenic response is triggered and leads to a progressive reduction of the $\beta$-cell mass.

$\left[92^{\bullet}, 93^{\circ}\right]$. This strategy of immunomodulation in T1D has been extensively discussed elsewhere [94].

Because of its antigen-specificity, the most attractive immunomodulating approach is the design of peptidebased therapeutic vaccines [95-97]. A recent randomized, placebo-controlled clinical trial has shown that two subcutaneous injections of GAD65 $(20 \mu \mathrm{g})$ in a standard vaccine formulation with alum (GAD-alum) contribute to the preservation of residual insulin secretion in recentonset T1D, but did not change the insulin requirement $[98,99]$. According to the novel knowledge gained in T1D pathogenesis and the central role of a thymus dysfunction in its development, the control of the autoimmune process could be obtained by (re)programing $\beta$-cell through the potent tolerogenic properties of the thymus, in particular the repertoire of thymic T1D-related self-antigens. According to this perspective, the profile of cytokine secretion was analyzed after presentation of Ins B9-23, a major T1D autoantigen [5,6], and the homologous sequence IGF-2 B11-25 derived from IGF-2, the dominant thymic self-antigen of the insulin family. This study was performed in PBMC cultures derived from DQ8positive T1 adolescents. First, InsB9-23 and IGF-2 B1125 were shown to have the same affinity and to compete for binding to DQ8 and DQ2 (Wücherpfennig and Geenen, unpublished data). Second, using ELISpot methodology, DQ8 presentation of IGF-2 B11 25 was found to induce a regulatory profile ( $\uparrow$ IL-10, $\uparrow$ IL-10/IFN- $\gamma$, and $\uparrow$ IL-4), statistically different from the profile induced by Ins B9-23. This regulatory profile could derive from a different cytokine profile secreted by Ins B9-23-reactive CD4+ T cells in response to IGF-2 B11-25, or from the recruitment and activation of IGF-2 specific Tregs. So, contrary to insulin, the 'altered self-IGF-2', IGF-2 and derived epitopes might be a much more appropriate choice for a novel type of a negative self-vaccination that associates competition for MHC presentation and regulatory responses downstream, as well as potential bystander suppression of autoimmune responses to other T1Drelated autoantigens. This hypothesis is currently being investigated by vaccination of NOD mice with recombinant human IGF-2 alone or in combination with adjuvants. A very recent study has shown that the combination 


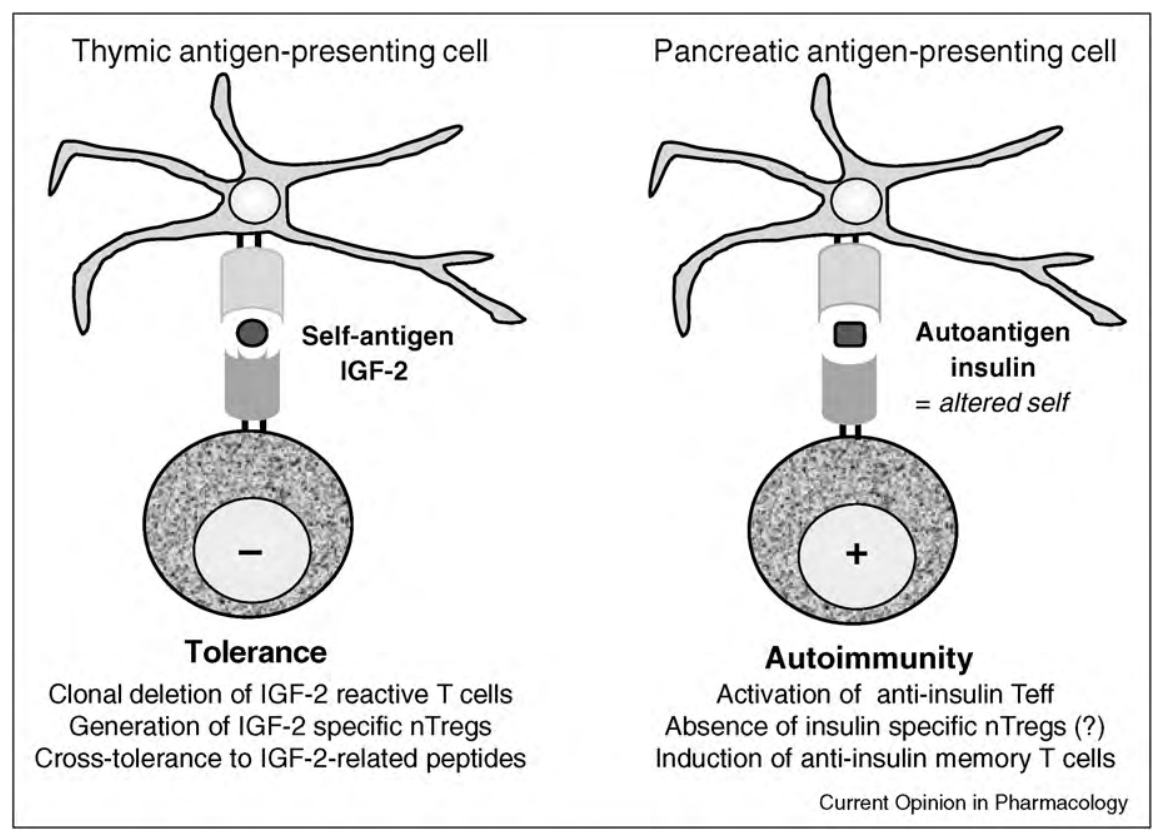

Principles of negative/tolerogenic self-vaccination. These principles are based on homology and crosstolerance between IGF-2 and insulin. Intrathymic presentation of IGF-2 as the self-antigen of the insulin family leads to clonal deletion of IGF-2 reactive T cells and generation of IGF-2 specific nTregs. The diabetogenic autoimmune response results from recognition of insulin (as 'altered IGF-2') and activation of anti-insulin Teff having escaped thymic censorship. It could also be facilitated by the unproved absence of insulin-specific nTregs. IGF- 2 antigenic epitopes compete with homologous insulin sequences for binding to MHC, and their recognition by anti-insulin TCRs might promote a regulatory response ( $\uparrow \mathrm{IL}-10$, $\uparrow \mathrm{IL}-4$ ) instead of an inflammatory Th1 profile.

of antigen-based therapy with FcR-nonbinding CD3specific monoclonal antibody strongly increased the activity of insulin-specific Foxp3+ CD4+ CD25+ Tregs. These cells could transfer dominant tolerance to immunocompetent recent-onset diabetic mice recipients, and they were shown to secrete IL-10, TGF- $\beta$, and IL-4, thus strongly suggesting induction of antigen-specific Tregs [100]. Finally, with regard to generation of islet $\beta$ cells from human induced pluripotent stem cells, IGF-2 was used with nicotinamide for the final differentiation of pancreatic exocrine/endocrine cells into insulin-producing cells [101]. It is notable that these results suggest that the same protein, IGF-2, can be employed both to regenerate the functional $\beta$-cell mass and to reprogram of immunological tolerance to islet $\beta$ cells.

\section{Conclusion}

The thymus plays a central role in the establishment of central immunological self-tolerance toward Langerhans' insulin-secreting islet $\beta$ cells, and there is now evidence that the development of T1D results from a breakdown of thymus-dependent tolerance of insulin-family derived epitopes. This knowledge should translate in the very near future to the design of novel tolerogenic/regulatory approaches aimed at restoring the immunological tolerance specific of islet $\beta$ cells, which represents an appealing strategy for both the prevention and the cure of T1D, one of the heaviest prices paid by the human species for having evolved the advantage of the extreme diversity and efficiency of adaptive immune responses against new biological threats.

\section{Conflict of interest statement}

VG is coinventor of IGF-2 related patents. No other conflict of interest relevant to this article was reported.

\section{Acknowledgements}

These studies are supported by the Fund Leon Fredericq for biomedical research at the University Hospital of Liege, by the Walloon Region (Project Waleo 2 Tolediab), by the Fund of Scientific Research (FSR, Brussels, Belgium), by the European Association for the Study of Diabetes (EASD, Düsseldorf, Germany), by the Juvenile Diabetes Research Federation, and by the European Commission-funded Integrated Project FP6 Euro-Thymaide LSHB-CT-2004-503410 (www.eurothymaide.org). Our gratitude is due to Professor Joseph G Verbalis, MD, PhD (Georgetown University, Washington, DC) for his critical reading of the manuscript. VG is research director at the FSR (Brussels, Belgium), professor of

Developmental Biology at the University of Liege, and clinical head at the Division of Endocrinology at the University Hospital of Liege.

\section{References and recommended reading}

Papers of particular interest, published within the period of review, have been highlighted as:

- of special interest

$\bullet$ of outstanding interest

1. Gepts W: Pathologic anatomy of the pancreas in juvenile diabetes mellitus. Diabetes 1965, 14:619-633. 
2. Bottazzo GF, Florin-Christensen A, Doniach D: Islet cell antibodies in diabetes mellitus with autoimmune polyendocrine deficiencies. Lancet 1974, 2:1279-1283.

3. Wenzlau JM, Juhl K, Yu L, Moua O, Sarkar SA, Gottlieb P, Rewers M, Eisenbarth GS, Jensen J, Davidson HW, Hutton JC: The cation efflux transporter $\mathrm{ZnT8}$ (Slc30A8) is a major autoantigen in human type 1 diabetes. Proc Natl Acad U S A 2007, 104:17040-17045.

4. Stadinski BD, Delong T, Reisdorph N, Reisdorph R, Powell RL, Armstrong M, Piganelli JD, Barbour G, Bradley B, Crawford F et al. Chromogranin $\mathrm{A}$ is an autoantigen in type 1 diabetes. Nat Immunol 2010, 11:225-232.

5. Nakayama M, Abiru N, Moriyama H, Babaya N, Liu E, Mao D, Yu L, Wegmann DL, Hutton JC, Elliott JF, Eisenbarth GS: Prime role for an insulin epitope in the development of type 1 diabetes in NOD mice. Nature 2005, 435:220-223.

6. Kent SC, Chen Y, Bregoli L, Clemmings SM, Kenyon NS, Ricordi C Hering BJ, Hafler DA: Expanded T cells from pancreatic lymph nodes of type 1 diabetic subjects recognize an insulin epitope. Nature 2005, 435:224-228.

7. Gale EAM, Bingley PJ: Autoimmune type 1 diabetes. In Immunoendocrinology in Health and Disease. Edited by Geenen V, Chrousos GP. New York: Marcel Dekker Inc; 2004:417-438.

8. Notkins A, Lernmark A: Autoimmune type 1 diabetes: resolved and unresolved issues. J Clin Invest 2001 108:1247-1252.

9. Martin S, Wolf-Eichbaum D, Duinkerken G, Scherbaum WA, Kolb H, Noordzij JG, Roep BO: Development of type 1 diabetes despite severe hereditary B-lymphocyte deficiency. N Engl J Med 2001, 345:1036-1040.

10. Roep BO: The role of $\mathbf{T}$ cells in the pathogenesis of type 1 diabetes: from cause to cure. Diabetologia 2003 , 46:305-321.

11. Arif S, Tree TI, Astill TP, Tremble JM, Bishop AJ, Dayan CM, Roep BO, Peakman M: Autoreactive T cell responses show proinflammatory polarization in diabetes but a regulatory phenotype in health. J Clin Invest 2004, 113:451-463.

12. Herold KC, Brooks-Worrell B, Palmer J, Dosch HM, Peakman M, Gottlieb P, Reijonen H, Arif S, Spain LM, Thompson C et al.: Validity and reproducibility of measurement of islet autoreactivity by T-cell assays in subjects with early type 1 diabetes. Diabetes 2009, 58:2588-2595.

13. Nerup J, Platz P, Andersen OO, Christy M, Lyngsoe J, Poulsen JE, Ryder LP, Nielsen LS, Thomsen M, Svejgaard A: HLA antigens and diabetes mellitus. Lancet 1974, 2:864-866.

14. Noble JA, Valdes AM, Cook M, Klitz W, Thomson G, Erlich HA: The role of HLA class II genes in insulin-dependent diabetes mellitus: molecular analysis of 180 Caucasian, multiplex families. Am J Hum Genet 1996, 59:1134-1148.

15. Lee KH, Wücherpfennig KW, Wiley DC: Structure of a human

-. insulin peptide/HLA-DQ8 complex and susceptibility to type 1 diabetes. Nat Immunol 2001, 2:501-507.

First structural demonstration that a dominant T1D autoantigenic epitope derived from insulin (Ins B9-23) is located in the binding pocket of the MHC-II alleles DQ8/DQ2 conferring major genetic susceptibility to T1D.

16. Nejentsev S, Howson JMM, Walker NM, Szeszko J, Field SF, Stevens HE, Reynolds $\mathrm{P}$, Hardy M, King E, Masters $\mathrm{J}$ et al.: Localization of type 1 diabetes susceptibility to the MHC class I genes HLA-B and HLA-A. Nature 2007, 450:887-892.

17. Bell Gl, Horita S, Karam JH: A polymorphism locus near the insulin gene is associated with insulin-dependent diabetes mellitus. Diabetes 1984, 33:176-183.

18. Bennett ST, Lucassen AM, Gough SCL, Powell EE, Undlien DE, Pritchard LE, Merriman ME, Kawaguchi $Y$, Dronsfield M, Pociot $F$ et al.: Susceptibility to human type 1 diabetes at IDDM2 is determined by tandem repeat variation at the insulin gene minisatellite locus. Nat Genet 1995, 9:284-292.

19. Nistico L, Buzzetti R, Pritchard LE, Van der Auwera B, Giovanni C, Bosi E, Martinez Larrad MT, Serrano-Rios M, Chow CC,
Cockram CS et al:: The CTLA4 region of chromosome 2q33 is linked to, and associated with, type 1 diabetes. Hum Mol Genet 1996, 5:1075-1080.

20. Waterhouse $P$, Penninger JM, Timms E, Wakeham A, Shahinian A,

- Lee KP, Thompson CB, Griesser H, Mak TW:

Lymphoproliferative disorders with early lethality in mice deficient in Ctla4. Science 1995, 270:985-988.

Definitive evidence that the T-cell surface molecule CTLA-4 acts as a negative regulator of T-cell activation and is crucial for immune homeostasis.

21. Bottini N, Musumeci L, Alonso A, Rahmouni S, Nika C,

- Rostamkhani M, McMurray J, Meloni GF, Lucarelli P,

Pellechia $\mathrm{M}$ et al.: A functional variant of lymphoid tyrosine phosphatase is associated with type 1 diabetes. Nat Genet 2004, 36:337-338.

First report that a single-nucleotide polymorphism (SNP) in PTPN22 encoding LYP, a suppressor of T-cell activation is associated with T1D.

22. Criswell LA, Pfeiffer KA, Lum RF, Gonzales B, Novitzke J, Kern M, Moser KL, Begovich AB, Carlton VEH, Li W et al.: Analysis of families in the Multiple Autoimmune Disease Genetics Consortium (MADGC) collection: the PTPN22 [620W] allele associates with multiple autoimmune phenotypes. Am J Hum Genet 2005, 76:561-571.

23. Vang $T$, Congia M, Macis MD, Musumeci L, Orru V, Zavattari $P$, Nika K, Tautz L, Tasken K, Cucca F et al.: Autoimmuneassociated lymphoid tyrosine phosphatase is a gain-offunction variant. Nat Genet 2005, 37:1317-1319.

24. Rieck M, Arechiga A, Onengut-Gumuscu S, Greenbaum C, Concannon P, Buckner JH: Genetic variation in PTPN22 corresponds to altered function of $T$ and $B$ lymphocytes. $J$ Immunol 2007, 179:4704-4710.

25. The Wellcome Trust Case Control Consortium: Genome-wide - association study of 14,000 cases of seven common diseases and 3,000 shared controls. Nature 2007, 447:661-678.

One of the largest genome-wide association (GWA) study that identified genetic loci for susceptibility to common diseases (T1D, T2D, rheumatoid arthritis, hypertension, Crohn's disease, coronary artery disease and bipolar disorder). Several loci were found to have shared between autoimmune and inflammatory diseases including T1D.

26. Qu HP, Montpetit A, Ge B, Hudson TJ, Polychronakos C: Toward further mapping of the association between the IL2RA locus and type 1 diabetes. Diabetes 2007, 56:1174-1176.

27. McCann JA, Xu YQ, Frechette R, Guazzarotti L, Polychronakos C: The insulin-like growth factor-II receptor gene is associated with type 1 diabetes: evidence of a maternal effect. J Clin Endocrinol Metab 2004, 89:5700-5706.

28. Bailey R, Cooper JD, Zeitels L, Smyth DJ, Yang JHM, Walker NM, Hyppönen E, Dunger DB, Ramos Lopez E, Badenhoop K et al.: Association of the vitamin D metabolism gene CYP27B1 with type 1 diabetes. Diabetes 2007, 56:2616-2621.

29. Karvonen M, Viik-Kajander M, Moltchanova E, Libman I, LaPorte R, Tuomilehto J: Incidence of childhood type 1 diabetes worldwide. Diabetes Mondiale (DiaMond) Project Group. Diabetes Care 2000, 23:1516-1526.

30. Bodansky HJ, Staines A, Stephenson C, Haigh D, Cartwright R: Evidence for an environmental effect in the aetiology of insulin-dependent diabetes in a transmigratory population. $\mathrm{Br}$ Med J 1992, 304:1020-1022.

31. Serrano-Rios M, Goday A, Martinez LT: Migrant populations and the incidence of type 1 diabetes mellitus: an overview of the literature with a focus on the Spanish-heritage countries in Latin America. Diabetes Metab Rev 1999, 15:113-132.

32. Patterson CC, Dahlquist GG, Gyürüs E, Green A, Soltesz G, and the EURODIAB Study Group: Incidence trends for childhood type 1 diabetes in Europe during 1989-2003 and predicted new cases 2005-20: a multicentre prospective registration study. Lancet 2009, 373:2027-2033.

33. Bach JF: The effect of infections on susceptibility to

- $\quad$ autoimmune and allergic diseases. N Engl J Med 2002, 347:911-920.

See annotation to Ref. [34 ${ }^{\circ}$. 
34. Zinkernagel RM: Maternal antibodies, childhood infections, - $\quad$ and autoimmune diseases. $N$ Engl J Med 2001, 345:1331-1335.

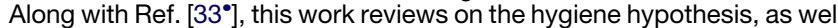
as on the influence of maternal antibodies upon the emergence of autoimmunity.

35. Anderson MS, Bluestone JA: The NOD mouse. Ann Rev Immunol 2005, 23:447-485.

36. Jun HS, Yoon JW: The role of viruses in type 1 diabetes: two distinct cellular and molecular mechanisms of virus-induced diabetes in animals. Diabetologia 2001, 44:271-285.

37. Jaeckel E, Manns M, Von Herrath M: Viruses and diabetes. Ann N $Y$ Acad Sci 2002, 958:7-25.

38. Hyöti $H$, Hiltunen $M$, Knip $M$, Laakonen $M$, Vähäsalo $P$, Karjalainen J, Koskela P, Roivanen M, Leinikki P, Hovi T: A prospective role of coxsackie $B$ and enterovirus infections in the pathogenesis of IDDM. Childhood Diabetes in Finland (DiMe) Study Group. Diabetes 1995, 44:652-667.

39. Yoon JW, Austin M, Onodera T, Notkins AL: Isolation of a virus from the pancreas of a child with diabetic ketoacidosis. NEngl $J$ Med 1979, 300:1173-1179.

40. Gamble DR, Kinsley ML, Fitzgerald MG, Taylor KW: Viral antibodies in diabetes mellitus. Br Med J 1969, 3:627-630.

41. Gamble DR, Taylor KW: Coxsackie B virus and diabetes. $B r$ Med J 1973, 1:289-290.

42. Clements GB, Galbraith DN, Taylor KW: Coxsackie B virus infection and onset of childhood diabetes. Lancet 1995 , 346:221-223.

43. Andreoletti L, Hober D, Hober-Vandenberghe C, Belaich S, Vantyghem MC, Lefebvre J, Wattre P: Detection of coxsackie B virus RNA sequences in whole blood samples from adult patients at the onset of type 1 diabetes mellitus. J Med Virol 1997, 52:121-127.

44. Chehadeh W, Kerr-Conte J, Patou F, Alm G, Lefebvre J, Wattre P, Hober D: Persistent infection of human pancreatic islets by coxsackievirus $B$ is associated with alpha-interferon synthesis in beta cells. J Virol 2000, 74:10153-10164.

45. Yin H, Berg AK, Westman J, Hellerström C, Frisk G: Complete nucleotide sequence of a coxsackievirus B4 strain capable of establishing persistent infection in human pancreatic islet cells: effects on insulin release, proinsulin synthesis, and cell morphology. J Med Virol 2002, 68:544-547.

46. Yin $\mathrm{H}$, Berg AK, Tuvemo $\mathrm{T}$, Frisk $\mathrm{G}$ : Enterovirus RNA is found in peripheral blood mononuclear cells in a majority of type 1 diabetic children at onset. Diabetes 2002, 51:1964-1971.

47. Horwitz MS, Bradley LM, Harbetson J, Krahl T, Lee J, Sarvetnick N Diabetes induced by coxsackievirus: initiation by bystander damage and not molecular mimicry. Nat Med 1998, 4:781-785.

48. Richter W, Mertens T, Schoel B, Muir P, Ritzkowsky A, Scherbaum WA, Boehm BO: Sequence homology of the diabetes-associated autoantigen glutamate decarboxylase with coxsackie B4-2C protein and heat shock protein 60 mediates no molecular mimicry of autoantibodies. J Exp Med 1994, 180:721-726.

49. Christen U, Edelmann KH, McGavern DB, Wolfe T, Coon B, Teague MK, Miller SD, Oldstone MB, von Herrath MG: A viral epitope that mimics a self antigen can accelerate but not initiate autoimmune diabetes. J Clin Invest 2004 , 114:1290-1298.

50. Honeyman MC, Stone NL, Falk BA, Nepom G, Harrison LC: Evidence for a molecular mimicry between human T-cell epitopes in rotavirus and pancreatic islet autoantigens. $J$ Immunol 2010, 184:2204-2210.

51. Horwitz MS, Sarvetnick N: Viruses, host responses, and autoimmunity. Immunol Rev 1999, 169:241-253.

52. Flodström M, Maday A, Balakrishna D, Cleary MM, Yoshimura A Sarvetnick N: Target cell defense prevents the development of diabetes after viral infection. Nat Immunol 2002, 3:373-384.
53. Chehadeh W, Weill J, Vantyghem MC, Alm G, Lefebvre J, Wattre P Hober D: Increased levels of interferon-alpha in blood of patients with insulin-dependent diabetes mellitus: relationship with coxsackievirus B infection. J Infect Dis 2000 181:1929-1939.

54. Field LL, Bonnevie-Nielsen V, Pociot F, Lu S, Nielsen TB, BeckNielsen H: OAS1 splice site polymorphism controlling antiviral enzyme activity influences susceptibility to type 1 diabetes. Diabetes 2005, 54:1588-1591.

55. Smyth DJ, Cooper JD, Bailey R, Field S, Burren O, Smink LJ, Guja C, lonescu-Tirgoviste C, Widmer B, Dunger DB et al:: A genome-wide association study of non-synonymous SNPs identifies a type 1 diabetes locus in the interferon-induced helicase (IFIH1) region. Nat Genet 2006, 38:617-619.

56. Kato H, Takeuchi O, Sato S, Yoneyama M, Yamamoto M, Matsui K Uematsu S, Jung A, Kawai T, Ishii KJ et al.: Differential roles of MDA5 and RIG-I helicases in the recognition of RNA viruses. Nature 2006, 441:101-105.

57. Geenen V, Kroemer G: Multiple ways to cellular immune tolerance. Immunol Today 1993, 14:573-575.

58. Martens H, Goxe B, Geenen V: The thymic repertoire of

- neuroendocrine-related self-antigens: physiological implications in T-cell life and death. Immunol Today 1996, 17:312-317.

Depending on their processing either as ligands for their cognate receptors expressed by thymic T cells, or as self-antigens presented by thymic $\mathrm{MHC}$ proteins, the thymic repertoire of neuroendocrine-related precursors recapitulates at the molecular level the dual role of the thymus in Tcell differentiation.

59. Kyewski B, Klein L: A central role for central tolerance. Annu Rev Immunol 2006, 24:571-606.

60. Dion ML, Bordi R, Zeidan J, Asaad R, Boulassel MR, Routy JP, Lederman MM, Sekaly RP, Cheynier R: Slow disease progression and robust therapy-mediated CD4+ T-cell recovery are associated with efficient thymopoiesis during HIV-1 infection. Blood 2007, 109:2912-2920.

61. Castermans E, Baron F, Willems E, Schaaf-Lafontaine N, Meuris N Gothot A, Vanbellinghen JF, Herens C, Seidel L, Geenen V et al.: Evidence for neo-generation of $T$ cells by the thymus after non-myeloablative conditioning. Haematologica 2008, 93:240-247.

62. Morrhaye G, Kermani H, Legros JJ, Baron F, Beguin $Y$,

- $\quad$ Moutschen M, Cheynier R, Martens HJ, Geenen V: Impact of growth hormone $(\mathrm{GH})$ deficiency and $\mathrm{GH}$ replacement upon thymus function in adult patients. PLOS ONE 2009, 4:e5668.

This clinical study demonstrates the close relationship between the integrity of the somatotrope GH/IGF-1 axis and the maintenance of thymopoiesis in adult patients.

63. Klein L, Hinterberger M, Wirnsberger G, Kyewski B: Antigen - presentation in the thymus for positive selection and central tolerance induction. Nat Rev Immunol 2009, 9:833-844.

An in-depth review of the cellular and molecular mechanisms implicated in thymic T-cell positive selection and induction of central immunological self-tolerance. The authors discuss how thymic stromal cells mediate Tcell selection in a cooperative rather than a redundant manner.

64. von Boehmer $\mathrm{H}$ : Central tolerance: essential for preventing autoimmune disease? Eur J Immunol 2009, 39:2313-2316.

65. Ashton-Rickardt PG, Bandeira A, Delaney JR, Van Kaer L, Pircher HP, Zinkernagel RM, Tonegawa S: Evidence for a differential avidity model of $\mathrm{T}$ cell selection in the thymus. Cell 1994, 76:651-663.

66. Vanneste $\mathrm{Y}$, Ntodou Thome A, Vandersmissen E, Charlet C,

- $\quad$ Franchimont D, Martens $\mathrm{H}$, Lhiaubet AM, Schimpff RM, Rostene W, Geenen V: Identification of neurotensin-related peptides in human thymic epithelial cell membranes and relationship with major histocompatibility complex class molecules. J Neuroimmunol 1997, 76:161-166.

This article shows that neurotensin (NT) is synthesized but is not secreted by human TECs in culture. A significant part of thymic NT could be eluted at basic $\mathrm{pH}$ from an affinity column prepared with an anti-MHC class monoclonal antibody. NT C-terminal sequence includes tyrosine, isoleucine and leucine residues. Each of these residues can be used in the 
anchorage to many MHC alleles, so that NT and derived C-termina fragments could behave as natural ligands for a majority of MHC class I alleles. This is also in agreement with the high degree of conservation of the NT-related C-terminal region throughout evolution.

67. Geenen V, Brilot F, Hansenne I, Martens H: Thymus and T-cells. In Encyclopedia of Neuroscience on CD-ROM, edn 3. Edited by Adelman G, Smith BH.New York: Elsevier; 20030-444-51432-5.

68. Derbinski J, Gäbler J, Brors B, Tierling S, Jonnakuty S, Hergenhahn M, Peltonen L, Walter J, Kyewski B: Promiscuous gene expression in thymic epithelial cells is regulated at multiple levels. J Exp Med 2005, 202:33-45.

69. Hansenne I, Renard-Charlet C, Greimers R, Geenen V: Dendritic - cell differentiation and tolerance to insulin-related peptides in Igf2-deficient mice. J Immunol 2006, 176:4651-4657.

This paper shows that Igf2 expression is required for the establishment of a complete tolerance to insulin.

70. Burnet FM: A reassessment of the forbidden clone hypothesis of autoimmune diseases. Aust J Exp Biol Med 1973, 50:1-9.

71. Robert F, Martens H, Cormann N, Benhida A, Schoenen J, Geenen V: The recognition of hypothalamo-neurohypophysial functions by developing T cells. Dev Immunol 1992, 2:131-140.

72. Kishimoto $\mathrm{H}$, Sprent $\mathrm{J}$ : A defect in central tolerance in NOD mice. Nat Immunol 2001, 2:1025-1031.

73. Zucchelli S, Holler P, Yamagata T, Roy M, Benoist C, Mathis D: Defective central tolerance induction in NOD mice: genomics and genetics. Immunity 2005, 22:385-396.

74. Kecha-Kamoun O, Achour I, Martens H, Collette J, Lefebvre PJ, Greiner DL, Geenen V: Thymic expression of insulin-related genes in an animal model of type 1 diabetes. Diab Metab Res Rev 2001, 17:146-152.

75. Geenen V, Lefebvre PJ: The intrathymic expression of insulinrelated genes: implications in physiopathology and prevention of type 1 diabetes. Diab Metab Rev 1998, 14:95-103.

76. Chentoufi AA, Polychronakos C: Insulin expression levels in the thymus modulate insulin-specific autoreactive T-cell tolerance. Diabetes 2002, 51:1383-1390.

77. Thebault-Baumont $K$, Dubois-Laforgue D, Krief $P$, Briand JP, Halbout P, Vallon-Geoffroy K, Morin J, Laloux V, Lehuen A, Carel JC et al.: Acceleration of type 1 diabetes mellitus in proinsulin 2-deficient NOD mice. J Clin Invest 2003, 111:851-857.

78. Moriyama H, Abiru N, Paronen J, Sikora K, Liu E, Miao D, Devendra D, Beilke J, Gianani R, Gill RG, Eisenbarth GS: Evidence for a primary islet autoantigen (preproinsulin 1) for insulitis and diabetes in the nonobese diabetic mouse. Proc Natl Acad Sci U $S$ A 2003, 100:10376-10381.

79. Vafiadis P, Bennett ST, Todd JA, Nadeau J, Grabs R, Goodyer CG

- Wickramasinghe S, Colle E, Polychronakos C: Insulin expression in human thymus is modulated by INS VNTR alleles at the IDDM2 locus. Nat Genet 1997, 15:289-292.

See annotation to Ref. $\left[8^{\circ}\right]$.

80. Pugliese A, Zeller M, Fernandez A Jr, Zalcberg LJ, Bartlett RJ,

- Ricordi C, Pietropaolo M, Eisenbarth GS, Bennett ST, Patel DD: The insulin gene is transcribed in human thymus and transcription levels correlate with allelic variation at the INS VNTR-IDDM2 susceptibility locus for type 1 diabetes. Nat Genet 1997, 15:293-297.

This work as well as Ref. $\left[7^{\circ}\right]$ show a positive relationship in human fetus between the presence of the T1D protective VNTR class III alleles and a higher content of INS mRNA in the thymus. Shorter VNTR alleles are associated with a reduction of thymic INS transcripts and predisposition to T1D.

81. Fan Y, Rudert WA, Grupillo M, He J, Sisino G, Trucco M: Thymus-

-. specific deletion of insulin induces autoimmune diabetes. EMBO J 2009, 28:2812-2824.

Complete deletion of thymic insulin was obtained by crossing Ins1 knockout mice with transgenic mice presenting Ins2 deletion in Aireexpressing medullary TECs. Both male and female pups developed autoimmune diabetes around three weeks only after birth. The presence of insulin-specific Teff was demonstrated with ELISpot assays and after adoptive cell transfer.
82. Nagamine K, Peterson P, Scott HS, Kudoh J, Minoshima S, Heino M, Krohn KJE, Lalioti MD, Mullis PE, Antonorakis SE et al.: Positional cloning of the APECED gene. Nat Genet 1997, 17:393-398

83. Finnish-German APECED Consortium: An autoimmune disease, APECED, caused by mutations in a novel gene featuring two PHD-type zinc-finger domains. Nat Genet 1997, 17:399-403.

84. Heino M, Peterson P, Silanpää N, Guerin S, Wu L, Anderson G Scott HS, Antonorakis SE, Kudoh J, Shimizu N et al.: RNA and protein expression of the murine autoimmune regulator gene (Aire) in normal. RelB-deficient and in NOD mouse. Eur J Immunol 2000, 30:1884-1893.

85. Ramsey C, Winqvist O, Puhakka, Halonen M, Moro A, Kämpe O,

- Eskelin P, Pelto-Huikko M, Peltonen L: Aire deficient mice develop multiple features of APECED phenotype and show altered immune response. Hum Mol Genet 2002, 11:397-409.

See annotation to Ref. [ $\left[7^{\circ \bullet}\right]$.

86. Anderson MS, Venanzi ES, Klein L, Chen Z, Berzins SP, Turley SJ,

- $\quad$ von Boehmer $\mathrm{H}$, Bronson R, Dierich A, Benoist C, Mathis D: Projection of an immunological self-shadow in the thymus by the Aire protein. Science 2002, 298:1395-1401.

See annotation to Ref. [ $\left[7^{\circ *}\right]$.

87. Hubert FX, Kinkel SA, Crewther PE, Cannon PZF, Webster KE,

- Link M, Uibo R, O'Bryan MK, Meager A, Forehan SP et al:: Airedeficient C57BL/6 mice mimicking the common human 13base pair deletion mutation present with only a mild autoimmune phenotype. J Immunol 2009, 182:3902-3918.

This study as well as Refs. $\left[85^{\circ}, 86^{\circ \bullet}\right]$ show that Aire deletion in mice is associated with a decreased transcription of many tissue-restricted antigens and an autoimmune phenotype targeting several peripheral organs. However, the degree of the autoimmune phenotype strongly depends on the genetic background of Aire ${ }^{-1-}$ mice.

88. Niki S, Oshikawa K, Mouri Y, Hirota F, Matsushima A, Yano M, Han M, Bando Y, Izumi K, Matsumoto M et al.: Alteration of intrapancreatic target-organ specificity by abrogation of Aire in NOD mice. J Clin Invest 2006, 116:1292-1301.

89. Brilot F, Chehadeh W, Charlet-Renard C, Martens H, Geenen V, Hober D: Persistent infection of human thymic epithelial cells by coxsackievirus B4. J Virol 2002, 76:5260-5265.

90. Brilot F, Geenen V, Hober D, Stoddart C: Coxsackievirus B4 infection of human fetal thymus cells. J Virol 2004 78:9854-9861.

91. Jaïdane H, Gharbi J, Lobert PE, Lucas B, Hiar R, M'Hadheb MB Brilot F, Geenen V, Aouni M, Hober D: Prolonged viral detection in blood and lymphoid tissues from coxsackievirus B4 E2 orally-inoculated mice. Microbiol Immunol 2006 50:971-974

92. Herold KC, Hagopian W, Auger JA, Poumian-Ruiz E, Taylor L,

- Donaldson D, Gitelman SE, Harlan DM, Xu D, Zivin RA Bluestone JA: Anti-CD3 monoclonal antibody in new-onset type 1 diabetes mellitus. N Engl J Med 2002, 346:1692-1698.

See annotation to Ref. [93\%]

93. Keymeulen B, Vandemeulebroecke E, Ziegler AG, Mathieu C,

- Kaufman L, Hale G, Gorus F, Goldman M, Walter M, Candon S et al:: Insulin needs after CD3-antibody therapy in new-onset type 1 diabetes. N Engl J Med 2005, 352:2598-2608.

This study as well as Ref. [92*] confirm that a short therapy of recent T1D patients with a humanized anti-CD3 monoclonal antibody preserves the residual $\beta$-cell mass and quantitatively reduces the needs for insulin therapy.

94. Chatenoud L, Bluestone JA: CD3-specific antibodies: a portal to the treatment of autoimmunity. Nat Rev Immunol 2007, 7:622-632.

95. Larche M, Wraith DC: Peptide-based therapeutic vaccines for allergic and autoimmune diseases. Nat Med 2006, 11:569-576.

96. Isaacs $\mathrm{J}$ : $\mathbf{T}$ cell immunomodulation - the Holy Grail of therapeutic tolerance. Curr Opin Pharmacol 2007, 7:418-425

97. Tian J, Kaufman DL: Antigen-based therapy for the treatment of type 1 diabetes. Diabetes 2009, 58:1939-1946. 
98. Agardh CD, Lynch KF, Palmer M, Link K, Lernmark A: GAD65 vaccination: 5 years of follow-up in a randomized dose-escalating study in adult-onset autoimmune diabetes. Diabetologia 2009, 52:1363-1368.

99. Ludvigsson J, Faresjö M, Hjorth M, Axelsson S, Cheramy M, Pihl M, Vaarala O, Forsander G, Ivarsson S, Johansson C et al.: GAD treatment and insulin secretion in recent-onset type 1 diabetes. N Engl J Med 2009, 359:1909-1920.
100. Bresson D, Togher L, Rodrigo E, Chen Y, Bluestone JA, Herold KC, von Herrath M: Anti-CD3 and nasal proinsulin combination therapy enhances remission from recent-onset autoimmune diabetes by inducing Tregs. J Clin Invest 2006, 116:1371-1381.

101. Tateishi K, Taranova O, Liang G, D'Alessio AC, Zhang Y: Generation of insulin-secreting islet-like clusters from human skin fibroblasts. J Biol Chem 2008, 283:31601-31607. 